\title{
In memoriam Peter Bräuer: His life and dedication to thermodynamics and adsorption
}

\author{
Prof. Dr. habil. Peter Bräuer (May 21st, 1939-April 29th, 2016)
}

Grit Kalies $^{1} \cdot$ Martin Bülow ${ }^{2} \cdot$ Mietek Jaroniec $^{3}$

Received: 4 August 2016/Accepted: 5 August 2016/Published online: 18 August 2016

(C) Springer Science+Business Media New York 2016

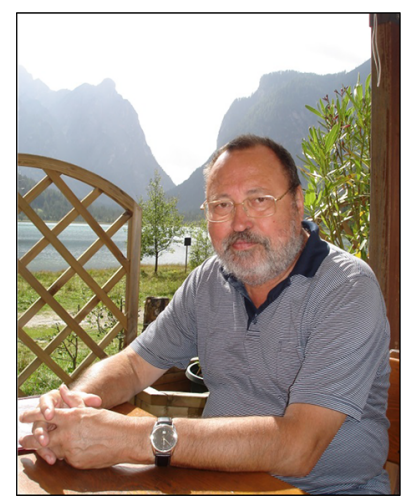

Dr. Peter Bräuer-a German university professor and scientist par excellence - passed away on April 29th, 2016, following a long and serious illness. He is survived by his wife Karin, two sons, one daughter and two grandsons.

Peter Bräuer was born on May 21st, 1939, the only child to the family of an artisan in Wartburg-Stadt Eisenach, a beautiful city in Thuringia, the heart of Germany. His father was an artisan, more a man of arts than a craftsman. His mother took care of the family as a housewife. The early years of Peter's life were marred by the deprivations of World War II and post-war time. Peter's education in Eisenach was comprised of primary school, 1945-1953, and high school, 1953-1957. In his elementary and high school education, music played a significant role. $\mathrm{He}$

Mietek Jaroniec

jaroniec@kent.edu

HTW University of Applied Sciences, Dresden, Germany

Ostseebad Dierhagen, Dierhagen, Germany

3 Kent State University, Kent, OH, USA became a member of the famous Eisenach Johann Sebastian Bach Choir and learned to play a variety of instruments. He especially loved playing the piano, finding himself most drawn to classical music and jazz. Peter enjoyed hiking through the countryside and mountains and visiting middle age-romantic towns, many of which were in the neighborhood of Eisenach.

Having obtained his high school diploma, the so-called Abitur, Peter became a qualified tuner at the Automobilwerk Eisenach (AWE), a widely known car manufacturer in the German Democratic Republic. One year later, Peter applied to the Friedrich Schiller University of Jena, not far from Eisenach. There he studied chemistry from 1958 to 1963 . He graduated in 1963 as a Diplomchemiker, an equivalent to a master's degree. The academic advisor of his thesis, entitled "Empiric Rules for Two-Atomic Molecules in Molecular Spectroscopy", was Prof. Dr. Heinz Dunken. This was exactly the title of Peter's first scientific paper, published in Z. Chem. (Leipzig) 5 (1965) 24.

Following a five-year period (1963-1968) of graduate research at the Lomonosov Moscow State University, he was awarded a Ph.D. in chemistry in 1969. His primary teachers were A. V. Kiselev and A. A. Lopatkin, famous professors of physical chemistry and world leaders in the areas of adsorption theory and surface science. Peter's doctoral thesis was entitled "Molecular Statistical Calculations of Adsorption on Zeolites". His dissertation was focused on the fundamental aspects of adsorption interactions between gases and structural units of microporous aluminosilicate lattices at the molecular level. This work, as part of the research carried out in the A. V. Kiselev laboratory, opened up new opportunities and stimulated further developments in utilizing molecular statistical thermodynamics for surface processes in regular microporous solids - by now extended to nanoporous ones - and on non- 
porous ionic crystals as well. These activities took place at the same time when R. M. Barrer carried out his pioneering research on zeolites and set up outstanding standards for education of adsorption scientists. At the Moscow State University, Peter contributed to the success of Kiselev's School, the first to use chemical modification of solid surfaces to tune their adsorption properties for specific applications. It was shown that chemical modification can serve as a powerful method to change the adsorption properties of materials, for instance to sufficiently reduce the size of mesopores and consequently, eliminate capillary condensation, which results in a change of the shape of adsorption isotherm. This research was essential for advancing the synthesis of novel materials with desired capacity and selectivity for adsorption-based chromatographic separations and purification of gas mixtures.

During Peter's stay in Moscow, he focused on the application of chemical thermodynamics for investigation of surface phenomena, especially adsorption. This type of study proved to be very useful in combination with spectroscopic methods developed at Jena University, to which Peter returned after graduating from the Lomonosov University. From 1968 to 1983, Peter was a member of the research team working in physical and surface chemistry in the Department of Chemistry (Sektion Chemie) at the Friedrich Schiller University of Jena, where his work resulted in dozens of research papers on various aspects of adsorption and surface science. During this time, Peter coauthored a technical monograph dedicated to "Physical Properties of Glass Surfaces" (VEB Deutscher Verlag für Grundstoffindustrie, Leipzig, 1981).

In 1979 Peter obtained a post-doctoral degree, the socalled habilitation, by defending his post-doctoral thesis "Utilization of Phenomenological and Statistical-thermodynamic Methods for Qualitative and Quantitative Assessment of Energetic Heterogeneity of Solid Surfaces by Means of Adsorption Isotherms". This work reflects the breadth of Peter's scientific interests, in particular, in the area of energetic heterogeneity of solid surfaces, as well as gas adsorption at very low pressures and spectroscopic methods. Peter continued a successful research career in this area, which resulted in his appointment as Lecturer (Assistant Professor) of physical chemistry at the Leipzig University (that time Karl Marx University) in 1983. Adsorption equilibria of both binary and ternary liquid mixtures and adsorption of gas mixtures at high pressures were further topics that widened the spectrum of Peter's research activities. One of the outcomes of this period is a rigorous thermodynamic description of high pressure gas adsorption. In 1989, Peter was appointed a Full Professor of Physical Chemistry and director of the famous Wilhelm Ostwald Institute in Leipzig. He held this position until 1994.
As "Ordinarius für Physikalische Chemie", Peter Bräuer became a highly recognized researcher in thermodynamics of adsorption, who optimally used his skills as an outstanding academic teacher and founder of a powerful research team and a well-equipped interfacial chemistry laboratory. Peter's approach toward solving various research problems involved careful consideration of the entire spectrum of chemical aspects rather than focusing on a few individual issues. As a scientist with international recognition he managed both domestic and international collaborations successfully. The main partners in Peter's international collaborations were the Kiselev Laboratory of Surface Science at the Moscow State University (Russia), the Department of Chemistry at Kent State University in Ohio (USA), and the Department of Theoretical and Physical Chemistry at the M. Sklodowska-Curie University in Lublin (Poland). A wonderful teacher, Peter attracted many talented young scientists and prepared them for a fruitful professional life. Numerous master and doctoral students in physical chemistry earned their degrees under his supervision.

Of all his areas of interest in physical chemistry, thermodynamics was Peter's great love. He enjoyed teaching thermodynamics of reversible and irreversible processes as well as statistical thermodynamics, which he did in a wonderful way that attracted more and more students to come and listen to his lectures. He did not use any overheads but deduced one complex formula after another from a simple one, to say from scratch, and built beautiful towers of logic using "chalk and blackboard" only, and his head and hands. Many of his best students ended up working with him later. His research team has been recognized at the national and international levels. Among numerous achievements, his application of the density functional theory to physical adsorption, which was a rapidly growing area in the 1990s, is a notable one. As a result, Peter Bräuer became the leader of a research program of the Deutsche Forschungsgemeinschaft (DFG) entitled "Physical Chemistry of Interfaces" at the Wilhelm Ostwald Institute in Leipzig.

Until 1994, Peter Bräuer held the position of "Ordinarius für Physikalische Chemie" at the Wilhelm Ostwald Institute. This period of fruitful work was followed by teaching physical chemistry as a permanent guest professor at the University of Rostock, from 1994 to 1995 . Back at Leipzig University, he joined the "Physics of Interfaces" team, where he began dealing with molecular mobility phenomena in nanoporous materials. However, thermodynamics fascinated him further. He attended numerous international conferences such as Fundamentals of Adsorption, International Symposia on the Effects of Surface Heterogeneity in Adsorption and Catalysis on Solids (ISSHAC, Poland), International Symposia on Nanoporous 
Materials (Canada), to name a few, and published many valuable works on the prediction of multicomponent liquid mixture equilibria and the calculation of adsorption energy distributions from experimental adsorption isotherms. Peter Bräuer and his group have published at least 130 scientific papers in international journals such as Adsorption, Journal of Colloid Interface Science, Journal of Physical Chemistry, Langmuir, Thin Solid Films, Surface Science Reports, and Chemical Physics Letters. Three nearly complete monographs covering almost the entire fields of reversible, irreversible and statistical thermodynamics belong to Peter's scientific legacy.

Colleagues of Peter and members of the Adsorption community will always remember him for his accuracy, love and dedication to science, his humaneness, his honesty and sincerity.

We thank Peter for the time he spent with us, and we mourn the loss of this outstanding scientist and teacher, and above all, a great man and friend. 